\title{
Impact of an intercropped melon/cowpea system on the coupling between soil bacterial community structure and chemical properties
}

Jessica Cuartero ( $\square$ jcuartero@cebas.csic.es )

Centro de Edafología y Biología Aplicada del Segura

Jose Antonio Pascual

Centro de Edafología y Biología Aplicada del Segura

Juana-María Vivo

Department of Statistics and Operations Research, University of Murcia

Onurcan Özbolat

Instituto de Biotecnología Vegetal, Universidad Politécnica de Cartagena

\section{Virginia Sánchez-Navarro}

Instituto de Biotecnología Vegetal, Universidad Politécnica de Cartagena

\section{Marcos Egea-Cortines}

Instituto de Biotecnología Vegetal, Universidad Politécnica de Cartagena

\section{Raúl Zornoza}

Instituto de Biotecnología Vegetal, Universidad Politécnica de Cartagena

\section{Maria Martinez Mena}

Centro de Edafología y Biología Aplicada del Segura

\section{Eloisa Garcia}

Centro de Edafología y Biología Aplicada del Segura

\section{Margarita Ros}

Centro de Edafología y Biología Aplicada del Segura

\section{Research Article}

Keywords: Cowpea, Melon, Bacterial community, Intercropping system, Nitrogen, Phosphorous

Posted Date: February 19th, 2021

DOI: https://doi.org/10.21203/rs.3.rs-256863/v1

License: (c) (i) This work is licensed under a Creative Commons Attribution 4.0 International License. Read Full License 


\section{Abstract}

A greater understanding of the relationship between soil microorganisms and intercropping systems could contribute to the optimization of land use, fostering sustainable and efficient agriculture. This study entails a comparative intercropping assay using cowpea (Vigna unguiculata) and melon (Cucumis melo) under organic management with different patterns and $30 \%$ less organic fertilization than that used in monocrops in the first year.

The intercropping system changed the bacterial community structure independently of the intercropping pattern and contributed to an increase in soil nitrogen, phosphorous content and melon crop yield. The intercropped systems were characterized by a higher abundance of Pseudomonas (Proteobacteria), which are related to nutrient cycling, and other beneficial microorganisms.

\section{Introduction}

Intercropping is a practice involving the simultaneous growing of two or more crops on the same land during the same growing season ${ }^{1}$. Nowadays this practice is becoming increasingly important for maintaining and increasing soil quality and subsequently crop productivity ${ }^{2}$. Intercropping has demonstrated advantages, including efficient nutrient acquisition; reduced pest, disease and weed damage; improved microbial diversity; and improved utilization of land resources ${ }^{3}$. Different types of intercropping and combination systems have been proposed to date. However, not all intercropping systems constitute improvements. It is particularly important to not use crops that compete for physical space, nutrients, water, or sunlight, and the environmental conditions in a given area and the crops or varieties available must be taken into account ${ }^{4}$. Maize is one of the predominant intercrops used, often combined with legume crops ${ }^{5}$. This combination makes it possible to develop an energy-efficient and sustainable system, as the legumes have an $\mathrm{N}$-fixing capability and more protein-yielding potential in the form of either grain or forage ${ }^{6}$. In arid environments, the legume crop cowpea (Vigna unguiculata L. $W a / p)$ is normally used because it is well adapted to drought and low fertility and can improve legume nitrogen uptake by nodulation ${ }^{7}$. Therefore, it can be intercropped not only with maize, but also millet, sorghum, and some other crops ${ }^{8,9}$.

Melon (Cucumis melo L.) is the main export crop in the region of Murcia (57\%). Intensive melon cultivation can generate soil and water degradation due to the excessive use of pesticides to reduce the impact of pathogens and the necessary application of synthetic fertilizers due to nutrient depletion ${ }^{10}$. Intercropping melon and cowpea could provide an important contribution to overcoming the challenges of developing both productive and environmentally friendly agricultural systems for melon cultivation.

Soil microorganisms are key drivers of many soil biological, chemical, and physical processes, such as soil structure formation, nutrient cycle, organic matter turnover, toxin accumulation or removal, and soilborne pathogen suppression ${ }^{11,12}$. Several studies have investigated the changes in the microbial 
characteristics of soils caused by intercropping ${ }^{13,14}$. However, changes in the soil microbial community resulting from melon-cowpea intercropping have not been studied in depth.

In this paper, we have studied changes in the soil bacterial community resulting from three different types of melon-cowpea intercropping systems and the relationship between these changes and soil chemical properties and crop yield compared to monoculture systems. We hypothesized that intercropping would improve crop yield, increase soil bacterial diversity, and change the soil community structure, and that this change would correlate with soil properties.

\section{Materials And Methods}

\subsection{Experimental design and sampling}

An intercropping experiment with melon and cowpea was performed under organic conditions in La Palma (Cartagena) ( $37^{\circ} 41^{\prime} 18^{\prime \prime} \mathrm{N} 0^{\circ} 56^{\prime} 60^{\circ} \mathrm{W}$ ), a province of Murcia (S.E. Spain), in May-August 2018. The field trial was conducted in a soil that had been uncultivated for at least the last five years prior to the study; the soil was classified as Haplic Calcisol (loamic, hypercalcic) IUSS (2015). The climate in the area of sturdy is semiarid Mediterranean, with a mean annual temperature of $18^{\circ} \mathrm{C}$, a mean annual precipitation of $275 \mathrm{~mm}$ and an annual potential evapotranspiration of $900 \mathrm{~mm}$.

The assayed treatments were as follows: i) melon (Cucumis melo) monocrop (M); ii) cowpea (Vigna unguiculata) monocrop (C); iii) mixed intercropping, with melon mixed with cowpea in the same row (MC1); iv) row intercropping at a ratio of 1:1 (melon:cowpea), alternating one melon row and one cowpea row (MC2); and $v$ ) row intercropping at a ratio of 2:1 (melon:cowpea), alternating two melon rows and one cowpea row (MC3). The field experiment was a completely randomized design with three plots per treatment, and each plot had a surface area of $150 \mathrm{~m}^{2}$. Melon seedlings were planted at a density of 0.4 plants $\mathrm{m}^{-2}$, with a spacing of $200 \mathrm{~cm}$ between rows and $120 \mathrm{~cm}$ between plants in both the monocropped and intercropped systems. The density of cowpea plants was 2.5 plants $\mathrm{m}^{-2}$ and 1.5 plants $\mathrm{m}^{-2}$ in the 1:1 row (MC2) and 2:1 row (MC3) systems, respectively. In the intercropped row systems, the cowpea rows were spaced $100 \mathrm{~cm}$ from the melon rows, and there were $20 \mathrm{~cm}$ between cowpea plants in the same row. In the mixed system (MC1), the cowpea density was 0.4 plants $\mathrm{m}^{-2}$ with one cowpea plant between melon plants in each row and spacing of $200 \mathrm{~cm}$ between rows and $120 \mathrm{~cm}$ between plants. The melon density was thus the same in the different treatments, but the cowpea density changed.

All crops were drip irrigated and grown under organic management. The melon plot $(M)$ received the equivalent of $3000 \mathrm{~kg} \mathrm{ha}^{-1}$ of organic fertilizer ( $\left.\mathrm{N} \mathrm{org}\right)(3.2 \% \mathrm{~N}$ and $7 \% \mathrm{~K} 20)$, and the cowpea plot (C) received the equivalent of $1875 \mathrm{~kg} \mathrm{ha}^{-1}$ of Norg. The mixed (MC1) and intercropped plots (MC2 and MC3) received $30 \%$ less Norg than the melon monocrop to assess the efficiency of the intercropping in reducing external fertilization needs. The melons and cowpeas were simultaneously harvested twice, on 
July 31, 2018 and August 6, 2018. The harvest was carried out manually, as is the tradition in the area, to avoid damaging the melon fruits.

Five random soil subsamples (0-10 cm depth) were collected with an auger from the plots on August 10, 2018, just after harvest. Soil samples in MC2 and MC3 were only collected from the melon rows. The samples were taken between two adjacent plants in all cases. The soil samples were separated into two aliquots, one of which was kept at ambient temperature for chemical analyses and the other stored in a cool box with ice for biological analysis. All samples were taken to the lab immediately. The soil was airdried for one week for chemical analyses and sieved at $<2 \mathrm{~mm}$. Soil for biological analysis was sieved at $<2 \mathrm{~mm}$ once in the lab and stored at $-20^{\circ} \mathrm{C}$.

\subsection{Soil properties and crop yield}

The soil pH and electrical conductivity (EC) were measured in deionized water $(1: 5 \mathrm{w} / \mathrm{v})$. The total organic carbon (TOC) and total nitrogen (TN) were determined using an elemental CHNS-O analyzer (EA-1108, Carlo Erba). Soil $\mathrm{NH}_{4}{ }^{+}$was extracted with $2 \mathrm{M} \mathrm{KCl}$ in a 1:10 soil:extractant ratio and calorimetrically measured ${ }^{16,17}$. Available $P(P)$ was measured using the Olsen method ${ }^{18}$. Available nutrients were measured using ICP-MS (Agilent 7500CE).

\subsection{Soil DNA extraction, PCR amplification and sequencing}

Soil DNA was extracted from $1 \mathrm{~g}$ of soil (wet weight) using the DNeasy Power Soil Kit (Qiagen). The quantity and quality of the DNA extracts were quantified using a Qubit 3.0 Fluorometer (Invitrogen, Thermo Fisher Scientific, USA) and a NanoDrop 2000 fluorospectrometer (Thermo Fisher Scientific, Waltham, MA, USA).

The bacterial community was determined via the next-generation sequencing of bacterial $16 \mathrm{~S}$ hypervariable regions using an Ion Torrent ${ }^{\mathrm{TM}}$ Personal Genome Machine ${ }^{\mathrm{TM}}$ (PGM) System. Bacterial 16S regions were amplified using an lon $16 \mathrm{~S}^{\mathrm{TM}}$ Metagenomics Kit (Thermo Fisher Scientific) with two different degenerate primer sets to amplify regions V2-8 and V3-6, V7-9. The amplified 16S amplicons were then processed using an Ion Xpress $^{\text {TM }}$ Plus Fragment Library Kit in combination with an Ion Xpress ${ }^{\text {TM }}$ Barcode Adapter 1-96 Kit (Thermo Fisher Scientific). All purification processes between incubation and amplification reactions of the library preparation were processed using DynaMag ${ }^{\mathrm{TM}}-2$ magnetic racks (Thermo Fisher Scientific) and an AMPure XP Purification Kit (Beckman Coulter). After library preparation and barcoding, we determined the size and concentration of the final libraries using an Agilent 2100 Bioanalyzer system and the Agilent High Sensitivity DNA kit. The sequencing templates were prepared using an lon One Touch 2 System and an Ion PGM ${ }^{\text {TM }}$ Hi-Q ${ }^{\text {TM }}$ View OT2 Kit (Thermo Fisher Scientific). The sequencing reaction was performed using lon Torrent PGM with an Ion PGMTM Hi-QTM View Sequencing Kit (Thermo Fisher Scientific).

\subsection{Sequencing data processing}

Bacterial raw sequences, barcodes and primers were trimmed according to the BaseCaller application. The sequences were denoised with $\mathrm{ACACIA}^{19}$, and low quality sequences were discarded using the 
Quantitative Insights into Microbial Ecology (QIIME) pipeline ${ }^{20}$ from the Microbiome Helper Virtual Box ${ }^{21}$. Briefly, bacterial sequences with a $Q<25$ were removed, and the retained sequences were then assigned to Operational Taxonomic Units (OTUs) based on 97\% similarity with the SILVA reference database after filtering chimeras using VSEARCH ${ }^{22}$ with the ribosomal database project (RDP database). Low-confident OTUs were removed.

The sequences were uploaded to the European Nucleotide Archive (ENA) with the study accession code PRJEB42624.

\subsection{Statistical analysis}

All tests were performed using $\mathrm{R}$ language ${ }^{23}$. Normality and homogeneity of variance assumptions were assayed by Shapiro-Wilk and Levene's tests using the $\mathrm{car}^{24}$ package. Mean comparisons were performed with one-way analysis of variance (ANOVA) followed by post-hoc tests, Tukey's honestly significant difference (HSD) for all-pair comparisons and Dunnett's comparisons for the control system. In the cases in which homoscedasticity was not met, Welch's test was performed using the 'pairwise.t.test' function with Bonferroni-Holm corrections for multiple comparisons. The robustness of the estimations was checked by the bootstrapping approach using 100 replicates. When data did not fit a normal distribution, non-parametric Kruskal-Wallis tests were performed, and if the assayed data were significant, a multiple comparison Z-values test was performed using the 'dunnTest' function with Benjamini-Hochberg corrections in the FSA package ${ }^{25}$.

Bacterial alpha diversity [Chao1 as richness and Shannon $\left(\mathrm{H}^{\prime}\right)$ as diversity index] was estimated on rarefied microbial data using the vegan package ${ }^{26}$.

A linear discriminant analysis (LDA) effect size (LEfSe) pipeline ${ }^{27}$, available at http://huttenhower.sph.harvard.edu/galaxy/, was used with the default parameters at all taxonomic levels to identify genera that were differentially abundant among the cultivation systems. Three different steps were performed using the following algorithm: i) a nonparametric Kruskal-Wallis test to detect the statistical differences between abundances; ii) a pairwise among subclasses using the Wilcoxon ranksum test to evaluate biological consistency; and iii) an LDA to estimate the effect size between abundances.

Principal coordinates analysis ( $\mathrm{PCOA}$ ) was used to visualize the variation in community composition by cultivation system based on the Bray-Curtis distance. To evaluate differences between the cropping systems, a Permutational Multivariate Analysis of Variance (PERMANOVA) was conducted using the 'betadisper' and 'adonis' functions with 999 permutations from the vegan package, followed by the 'pairwise.adonis' function with Benjamini-Hochberg corrections for multiple comparisons between specific cultivation systems from the pairwiseAdonis package ${ }^{28}$ when the homogeneity of variance assumption was met. In the cases in which homoscedasticity was not fulfilled, an Analysis of Similarities (ANOSIM) was carried out instead. Relationships between the bacterial community and the rest of the parameters were determined using the 'bioenv' function from the vegan package to find the best subset 
of parameters (using Euclidean distance) that had a maximum correlation with the community dissimilarity matrix ${ }^{29}$. Redundancy analysis (RDA) was performed through the vegan package to visualize the correlation between OTUs and physico-chemical, biological and harvest parameters. The OTU abundance was Hellinger transformed prior to analysis with the retained variables from the bioenv procedure ${ }^{30}$, which was performed via the 'bioenv' function based on Spearman's rank correlation coefficient. To equalize the number of replicates for 'bioenv' and 'rda', the function 'sample_n' in the dplyr package $^{31}$ was used.

\section{Results}

\subsection{Effects of intercropping on melon crop yield}

The intercropped melon systems showed a significantly higher melon yield (MC1 74\%, MC3 64\%) and number of melons (MC3 52\%, MC1 40\% and MC2 33\%) than the monocrop (M) (Table 1). The cowpea yield, on the other hand, was higher in the monocrop system than in the intercropping systems (Table 1). 
Table 1

Physico-chemical and chemical soil properties and harvest parameters in the intercropping systems

\begin{tabular}{|c|c|c|c|c|c|c|c|}
\hline & C & M & MC1 & MC2 & MC3 & Anova & $\begin{array}{l}\text { Kruskal- } \\
\text { Wallis }\end{array}$ \\
\hline $\mathrm{pH}$ & $8.4 \pm 0.0$ & $8.5 \pm 0.0$ & $8.4 \pm 0.0$ & $8.3 \pm 0.0$ & $8.4 \pm 0.0$ & ns & - \\
\hline $\mathrm{EC}\left(\mu \mathrm{S} \mathrm{cm} \mathrm{cm}^{-1}\right)$ & $307 \pm 6$ & $290 \pm 2$ & $332 \pm 30$ & $298 \pm 17$ & $\begin{array}{l}299 \pm \\
37\end{array}$ & - & ns \\
\hline TOC $\left(\mathrm{g} \mathrm{kg}^{-1}\right)$ & $\begin{array}{l}11.8 \pm \\
0.3 \mathrm{a}\end{array}$ & $\begin{array}{l}9.5 \pm 0.1 \\
b\end{array}$ & $\begin{array}{l}11.2 \pm \\
0.4 \mathrm{ab}\end{array}$ & $\begin{array}{l}11.1 \pm \\
0.2 \mathrm{ab}\end{array}$ & $\begin{array}{l}11.9 \pm \\
0.2 \mathrm{a}\end{array}$ & - & * \\
\hline $\mathrm{TN}\left(\mathrm{mg} \mathrm{kg}{ }^{-1}\right)$ & $\begin{array}{l}1.3 \pm 0.0 \\
\mathrm{a}\end{array}$ & $\begin{array}{l}1.1 \pm 0.0 \\
b\end{array}$ & $\begin{array}{l}1.3 \pm 0.0 \\
a\end{array}$ & $\begin{array}{l}1.3 \pm 0.0 \\
a\end{array}$ & $\begin{array}{l}1.3 \pm 0.0 \\
a\end{array}$ & - & * \\
\hline $\mathrm{NH}_{4}^{+}\left(\mathrm{mg} \mathrm{kg}^{-1}\right)$ & $\begin{array}{l}0.53 \pm \\
0.18 \mathrm{~b}\end{array}$ & $\begin{array}{l}0.88 \pm \\
0.00 \mathrm{~b}\end{array}$ & $\begin{array}{l}1.83 \pm \\
0.10 \mathrm{ab}\end{array}$ & $\begin{array}{l}3.36 \pm \\
0.63 \mathrm{ab}\end{array}$ & $\begin{array}{l}4.48 \pm \\
0.72 \mathrm{a}\end{array}$ & - & $\star \star$ \\
\hline $\mathrm{Ca}\left(\mathrm{mg} \mathrm{kg}^{-1}\right)$ & $\begin{array}{l}1579 \pm \\
236 a\end{array}$ & $\begin{array}{l}1540 \pm \\
39 a\end{array}$ & $\begin{array}{l}1432 \pm \\
297 a\end{array}$ & $\begin{array}{l}908 \pm 77 \\
b^{\star \star}\end{array}$ & $\begin{array}{l}951 \pm \\
22 b^{\star \star}\end{array}$ & ** & - \\
\hline$M g(m g ~ k g-1)$ & $\begin{array}{l}360 \pm \\
75 a b\end{array}$ & $\begin{array}{l}325 \pm \\
62 \mathrm{ab}\end{array}$ & $\begin{array}{l}426 \pm 93 \\
a\end{array}$ & $\begin{array}{l}244 \pm 35 \\
b\end{array}$ & $\begin{array}{l}242 \pm 4 \\
b\end{array}$ & * & - \\
\hline $\mathrm{K}\left(\mathrm{mg} \mathrm{kg}^{-1}\right)$ & $\begin{array}{l}325 \pm \\
83\end{array}$ & $\begin{array}{l}344 \pm \\
70\end{array}$ & $\begin{array}{l}430 \pm \\
105\end{array}$ & $263 \pm 9$ & $\begin{array}{l}279 \pm \\
36\end{array}$ & ns & - \\
\hline $\mathrm{Na}\left(\mathrm{mg} \mathrm{kg}^{-1}\right)$ & $\begin{array}{l}254 \pm 2 \\
a b\end{array}$ & $\begin{array}{l}268 \pm \\
43 a\end{array}$ & $\begin{array}{l}271 \pm 13 \\
a\end{array}$ & $\begin{array}{l}159 \pm 21 \\
a b\end{array}$ & $\begin{array}{l}133 \pm \\
14 b\end{array}$ & - & * \\
\hline$P\left(\mathrm{mg} \mathrm{kg}^{-1}\right)$ & $18 \pm 5 b$ & $23 \pm 1 b$ & $\begin{array}{l}62 \pm 2 \\
a^{\star \star \star}\end{array}$ & $\begin{array}{l}58 \pm 3 \\
a^{\star \star \star}\end{array}$ & $\begin{array}{l}49 \pm 9 \\
a^{\star \star \star}\end{array}$ & $* * *$ & - \\
\hline $\begin{array}{l}\text { Number of melons } \\
\text { (num ha-1) }\end{array}$ & - & $\begin{array}{l}5548 \pm \\
46 \mathrm{~b}\end{array}$ & $\begin{array}{l}7752 \pm \\
140 \mathrm{ab}\end{array}$ & $\begin{array}{l}7395 \pm \\
39 a b\end{array}$ & $\begin{array}{l}8455 \pm \\
547 a\end{array}$ & - & * \\
\hline $\begin{array}{l}\text { Number of melons } \\
\text { (num ha-1) }\end{array}$ & - & $\begin{array}{l}5548 \pm \\
46 \mathrm{~b}\end{array}$ & $\begin{array}{l}7752 \pm \\
140 \mathrm{ab}\end{array}$ & $\begin{array}{l}7395 \pm \\
39 \mathrm{ab}\end{array}$ & $\begin{array}{l}8455 \pm \\
547 a\end{array}$ & - & * \\
\hline $\begin{array}{l}\text { Cowpea Yield } \\
\left(\mathrm{kg} \mathrm{ha}^{-1}\right)\end{array}$ & $\begin{array}{l}2053 \pm \\
59 a\end{array}$ & - & $\begin{array}{l}106 \pm 39 \\
b\end{array}$ & $\begin{array}{l}871 \pm 82 \\
C\end{array}$ & $\begin{array}{l}463 \pm \\
60 \mathrm{~d}\end{array}$ & $\star \star \star *$ & - \\
\hline \multicolumn{8}{|c|}{ 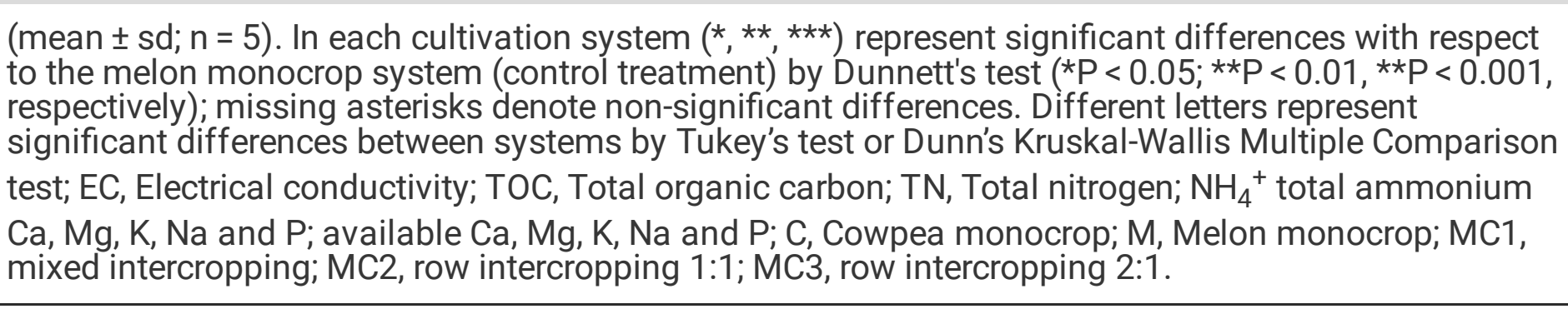 } \\
\hline
\end{tabular}

3.2. Effects of intercropping on bacterial community diversity and composition 
After filtering, 821,795 reads were yielded and 6,676 OTUs were identified with $97 \%$ similarity for the bacterial community. No significant differences were found in the Shannon or Chao1 diversity indexes between cropping systems (Supplementary Fig. 1). Sequence analyses at the phylum and genus taxonomic levels are shown in Fig. 1A and Fig. 1B.

Proteobacteria was the most abundant phylum (40\%), followed by Actinobacteria (31\%). It is noticeable that Proteobacteria and Bacteroidetes were significantly more abundant and Actinobacteria significantly less abundant in intercropped soil systems (MC1, MC2 and MC3) than in monocrop soils ( $M$ and $C$ ) (Supplementary Table 1). The other dominant phyla were Acidobacteria (10\%), Firmicutes (7\%), Gemmatimonadetes (5\%), Planctomycetes (2\%), Chloroflexi (2\%), Bacteroidetes (1\%) and Nitrospirae (1\%), none of which showed significantly different abundances between the monoculture and intercropping systems (Supplementary Table 1; Fig. 1A).

The most abundant genera in the different cropping systems were Bacillus (23.6\%), Sphingomonas (17.8\%), Streptomyces (12.0\%), Nocardioides (10.1\%), Pseudomonas (9.0\%), Ammoniphilus (6.2\%), Rubrobacter (6.0\%), Skermanella (5.4\%), Thauera (4.0\%) and Solirubrobacter (3.5\%) (Fig. 1B; Supplementary Table 2). Pseudomonas genera abundance was significantly higher in intercropped systems ( $\mathrm{MC} 1, \mathrm{MC} 2$ and $\mathrm{MC} 3$ ) than in monocrop systems ( $\mathrm{C}$ and $\mathrm{M})$, whereas Rubrobacter and Solirubrobacter genera abundance was lower (Supplementary Table 2). Sphingomonas and Skermanella were significantly more abundant in MC2, Thaurera in MC1 and Ammoniphilus in M.

Bacterial community structures were distinctly grouped by cropping system on a PCoA plot (Fig. 2). Moreover, the bacterial community structure in the monocrop systems ( $M$ and $C$ ) differed significantly ( $F$ $=2.7262 ; P=0.001)$ from that in the intercropping systems (MC1, MC2 and MC3). This difference was confirmed by pairwise comparison (Supplementary Table 3 ).

Concerning the specific gene community related to $\mathrm{N}$ cycles, strong differences were found in AMOA, NARG $(p<0.05)$ and NIRK ( $<0.01)$ genes. In general, the log copies of these three genes were higher in monocropping systems ( $\mathrm{M}$ and $\mathrm{C}$ ) than in intercropped systems (MC1, MC2 and MC3). Among the three intercropping patterns, MC2 showed the lowest values (Fig. 3; Supplementary Table 4).

LDA effect size analysis revealed 20 predominant genera in the melon monocrop (M): Blastococcus, Geofermatophilus, Kribella, Kineococcus, Actinoplanes, Micromonospora, Actinophytocola, Saccharomonospora, Nonomuraea, Actinomadura, Rubrobacter, Gaiella, Parviterribacter, Solirubacter, Tumebacillus, Gemmatimonas, Microvirda, Rubellimicrobium, Vulcaniibacterium and Opitutus. In the cowpea monocrop (C), on the other hand, only four genera were predominant: Pseudonocardia, Hyphomicrobium, Methylotenera and Phaselicystis. In the intercropped systems, five genera were selected as a predominant in MC1 (Peptoclostridium, Turicibacter, Amphiplicatus, Ralstonia and Stenotrophomonas); one genus was predominant in MC2 (Leptolyngbya); and one genus was predominant in MC3 (Piscinibacter). (Fig. 4; Supplementary Table 5).

\subsection{Effect of intercropping on soil properties}


Significant differences were found in some of the physicochemical and chemical soil properties (Table 1). Compared to the melon monocrop (M), TN was significantly $(p<0.05)$ higher in all the intercropped systems (MC1, MC2 and MC3) and the cowpea monocrop (C). $\mathrm{NH}_{4}{ }^{+}$was also higher in all the intercropped systems assayed than in the monocrops, but it was only significantly higher for the MC3 treatment $(p<0.05)$. The TOC content was significantly $(p<0.05)$ higher in MC3 and $C$ than in the other two melon intercropping systems (MC1, MC2) and the melon monocrop (M). The available $\mathrm{P}$ content was significantly $(p<0.001)$ higher in the intercropped systems $(M C 1, M C 2$ and $M C 3)$ than in both monocrops ( $\mathrm{M}$ and $\mathrm{C}$ ). Available $\mathrm{Mg}$ and $\mathrm{Na}$ were significantly higher $(\mathrm{p}<0.05)$ in $\mathrm{MC1}$ than in the other treatments, and available Ca was significantly higher in $\mathrm{MC1}, \mathrm{M}$ and $\mathrm{C}$. No significant differences were observed in available K (Table 1).

\subsection{Relationships between soil properties and the bacterial community}

Redundancy analysis (RDA) (Fig. 5) revealed a relationship between the bacterial community structure, soil properties and crop yield. The TN, AmoA, available $\mathrm{Na}$ and $\mathrm{P}$ and melon yield appeared to be strongly correlated with the bacterial community. Namely, the P content, melon crop yield, available $\mathrm{Na}$, and AmoA abundance were correlated with the first axis. The TN was correlated with the second axis. Monocrops showed clear divergence from the intercropping systems, while the latter could not be easily separated. Significant correlation was observed between different genera and the chemical and harvest parameters of the intercropping systems: Pseudomonas (r $0.69 \mathrm{P}<0.01 ; \mathrm{r} 0.70, \mathrm{P}<0.01 ; \mathrm{r} 0.68, \mathrm{P}<0.05$ ) with $\mathrm{P}, \mathrm{TN}$ and $M$. yield respectively.

\section{Discussion}

Intercropping is considered to be an environmentally friendly cropping system that can improve crop yield as well as water and nutrient-use efficiency ${ }^{32,33}$. Crops have different needs, so it is especially important to combine them in the right way to obtain yield improvements. As far as we know, the melon-cowpea intercropping system has not been studied in depth, nor have intercropping patterns between these two crops. However, this combination could be an important choice for sustainable agriculture management, given that cowpea is a legume, which fixes atmospheric nitrogen and thus supplies it to companion plants like watermelon or melon that at the same time provide soil shading to conserve water moisture ${ }^{34}$.

The intercropping system assayed was found to increase melon yield and the number of melons produced compared to melon monocrops starting from the first year of experimentation. Moreover, the intercrops used $30 \%$ less fertilization than the monocrop. This increase in melon yield could be due to a higher nitrogen disposal from cowpea rhizosphere, which, it is should be higher in soils with low $\mathrm{N}$ fertilization addition ${ }^{35}$. This fact has previously been observed in other cowpea intercrop relationships, such as cowpea-maize ${ }^{36}$, cowpea-sorghum ${ }^{37}$ and cowpea-cassava ${ }^{38}$. The cropping patterns and $\mathrm{N}$ fertilization rates can alter soil conditions, which subsequently influence the abundance of functional $\mathrm{N}$ cycling genes ${ }^{39}$. In our study, we also observed a decreasing trend in nitrification and denitrification processes in the three intercropped systems compared to the monocrops. This decrease in the 
intercropping systems could allow for sustainable nutrient use, diminishing nitrate losses due to leaching and $\mathrm{N}$ oxide emissions ${ }^{40}$.

In general, legume crops included in intercropping systems improve $P$ availability and soil organic carbon $^{41}$, mostly through root exudates, nodules, and the sloughing off of root cells and root turnover during the growing season ${ }^{42}$. Roots excrete larger amounts of protons and carboxylates (malonate, malate, and citrate), which would facilitate root-borne phosphatases to hydrolyze organic $\mathrm{P}^{43}$. This could be supported by a high abundance of phosphate-solubilizing bacteria like Pseudomonas, which are more abundant in intercropped soils, as observed previously by ${ }^{44}$, that correlated with available P, TN and melon yield. Moreover, the presence of several phosphate-solubilizing bacteria like Bacillus in both the monocrops and intercropping systems could also influence in this behavior, as has been observed by Chen et al. (2006) ${ }^{45}$ and Panhwar et al. $(2014)^{46}$.

It is important to note that soil microbial community composition is significantly correlated with changes in soil chemical properties ${ }^{47,48}$. In this study, the TN, available $\mathrm{Na}$ and $\mathrm{P}$ content, as AmoA abundance and melon crop yield play important roles in changes in the microbial community structure. Our findings could indicate that nutrient changes subsequently affect the carbon- and nitrogen-use efficiency of bacteria. Generally, an increase in soil microbial diversity is beneficial to soil function and health, but no differences were detected through diversity or richness estimators, indicating that our hypothesis was not validated. Until now, there is no consensus about changes in alpha diversity caused by intercropping systems, since some researchers have reported that some intercropping systems can increase diversity 1,49 , while others have reported no significant changes 50,51 .

On the other hand, we found significant differences in the bacterial community structure between intercropping and monocrop systems, although not between the different intercropping patterns. These differences showed the influence of cowpea on the bacterial structure of the melon crop, suggesting that cowpea could play an important role in maintaining agricultural ecosystem stability and improving crop growth $^{52}$. The dominant taxonomic groups identified in the soils assayed were Proteobacteria, Actinobacteria, Acidobacteria, Firmicutes, Gemmatimonadetes, Planctomycetes, Chloroflexi, Bacteroidetes and Nitrospirae, all depicted as common inhabitants of soil ${ }^{53}$. A higher relative abundance of Proteobacteria and Bacteriodetes and lower abundance of Actinobacteria in the intercropping systems than in the monocrop systems indicated that both plant species and planting patterns can change the abundance of dominant bacterial phyla ${ }^{50,54,55}$. Moreover, several plant beneficial microorganisms, identified as Pseudomonas, were higher in the intercropped soils, as were Bacillus, Streptomyces and Sphingomonas ${ }^{56,57}$.

LEfSe analysis indicated which microorganisms are significantly associated with the different cropping systems. The highest bacterial identified in the melon monocrop including Blastococcus, Geodermatophilus, Kineococcus, Actinoplanes, Kribella or Gemmatimonas. All of which have been reported as drought-resistant microorganisms ${ }^{58,59}$. On the other hand, only five bacteria were associated 
with the intercropping system, which indicates that changes are occurring. Moreover, these changes do not depend too much on the specific intercropping pattern. The fact that these bacteria did not have a greater abundance than in the monocrops is likely due to the high resilience of bacterial community to changes ${ }^{60}$. These results indicate that one year of intercropping, which has been studied here, is not enough to result in a significant amount of associated microorganisms. It would be expected that repetitive intercropping in the same soils would increase a different microbial pattern.

\section{Conclusion}

The introduction of cowpea in an intercropping system with melon in a short-term experiment resulted in a sustainable cropping system with decreased external input use and an increase in melon yield. The intercropping system changed the bacterial community structure, which contributed to an increase in soil TN and P concentrations and melon crop yield. The intercropped systems were characterized by a higher abundance of Pseudomonas (Proteobacteria), which are related to nutrient cycling and beneficial microorganisms. Further long-term analysis in these intercropping systems will be needed to reinforce findings on the positive interaction between cowpea and melon and to study more in depth which intercropping pattern farmers can choose according to their necessities.

\section{Declarations}

\section{Competing Interests}

The author(s) declare no competing interests.

\section{Acknowledgements}

This work was supported by the AsociaHortus project [AGL2017-83975-R] funded by the Spanish Ministry of Science, Innovation and Universities, and the European Commission Horizon 2020 project Diverfarming [grant agreement 728003]. Raúl Zornoza acknowledges the financial support from the Spanish Ministry of Science, Innovation and Universities through the "Ramón y Cajal" Program [RYC2015-18758].

\section{References}

1. Zhou, X., Yu, G. \& Wu, F. Effects of intercropping cucumber with onion or garlic on soil enzyme activities, microbial communities and cucumber yield. Eur. J. Soil Biol. 47, 279-287 (2011).

2. Singh, K., Mishra, A. K., Singh, B., Singh, R. P. \& Patra, D. D. Tillage effects on crop yield and physicochemical properties of sodic soils. L. Degrad. Dev. 27, 223-230 (2016).

3. Mousavi, S. R. \& Eskandari, H. A general overview on intercropping and its advantages in sustainable agriculture. J. Appl. Environ. Biol. Sci. 1, 482-486 (2011). 
4. Lithourgidis, A. S., Vlachostergios, D. N., Dordas, C. A. \& Damalas, C. A. Dry matter yield, nitrogen content, and competition in pea-cereal intercropping systems. Eur. J. Agron. 34, 287-294 (2011).

5. Manasa, P., Maitra, S. \& Reddy, M. D. Effect of Summer Maize-Legume Intercropping System on Growth, Productivity and Competitive Ability of Crops. Int. J. Manag. Technol. Eng. 8, 2871-2875 (2018).

6. Maitra, S., Palai, J. B., Manasa, P. \& Kumar, D. P. Potential of Intercropping System in Sustaining Crop Productivity. Int. J. Agric. Environ. Biotechnol. 12, 39-45 (2019).

7. Li, L. et al. Diversity enhances agricultural productivity via rhizosphere phosphorus facilitation on phosphorus-deficient soils. Proc. Natl. Acad. Sci. 104, 11192-11196(2007).

8. Nelson, W. C. D., Hoffmann, M. P., Vadez, V., Roetter, R. P. \& Whitbread, A. M. Testing pearl millet and cowpea intercropping systems under high temperatures. F. Crop. Res. 217, 150-166 (2018).

9. Chimonyo, V. G. P., Modi, A. T. \& Mabhaudhi, T. Simulating yield and water use of a sorghum-cowpea intercrop using APSIM. Agric. Water Manag. 177, 317-328 (2016).

10. Li, J. Nitrate leaching loss from soil and nutrient utilization by tomato in protected field. Chinese J. Appl. Environ. Biol. 7, 126-129 (2001).

11. Blagodatskaya, E. \& Kuzyakov, Y. Active microorganisms in soil: critical review of estimation criteria and approaches. Soil Biol. Biochem. 67, 192-211 (2013).

12. Bever, J. D., Platt, T. G. \& Morton, E. R. Microbial population and community dynamics on plant roots and their feedbacks on plant communities. Annu. Rev. Microbiol. 66, 265-283 (2012).

13. Li, S. \& Wu, F. Diversity and co-occurrence patterns of soil bacterial and fungal communities in seven intercropping systems. Front. Microbiol. 9, 1521 (2018).

14. Jin, P., Ren, B., Wang, X. C., Jin, X. \& Shi, X. Mechanism of microbial metabolic responses and ecological system conversion under different nitrogen conditions in sewers. Water Res. 186, 116312 (2020).

15. WRB, I. U. of S. S. W. G. World reference base for soil resources 2014 (update 2015), international soil classification system for naming soils and creating legends for soil maps. World Soil Resour. Reports, FAO, Rome(2015).

16. Keeney, D. R. \& Nelson, D. W. Nitrogen-inorganic forms. Methods Soil Anal. Part 2 Chem. Microbiol. Prop. 9, 643-698 (1983).

17. Kandeler, E. \& Gerber, H. Short-term assay of soil urease activity using colorimetric determination of ammonium. Biol. Fertil. Soils. 6, 68-72 (1988).

18. Olsen, S. R. Estimation of available phosphorus in soils by extraction with sodium bicarbonate(US Department of Agriculture, 1954).

19. Bragg, L., Stone, G., Imelfort, M., Hugenholtz, P. \& Tyson, G. W. Fast, accurate error-correction of amplicon pyrosequences using Acacia. Nat. Methods. 9, 425 (2012).

20. Caporaso, J. G. et al. QIIME allows analysis of high-throughput community sequencing data. Nat. Methods. 7, 335 (2010). 
21. Comeau, A. M., Douglas, G. M. \& Langille, M. G. I. Microbiome helper: a custom and streamlined workflow for microbiome research. MSystems 2(2017).

22. Rognes, T., Flouri, T., Nichols, B., Quince, C. \& Mahé, F. VSEARCH: a versatile open source tool for metagenomics. PeerJ. 4, (2016). e2584

23. Team, R. C. R: A language and environment for statistical computing. (2020).

24. Fox, J. et al. The car package. R Found. Stat. Comput.(2007).

25. Ogle, D. \& Ogle, M. D. Package 'FSA'.CRAN Repos1-206(2017).

26. Oksanen, J. et al. The vegan package. Community Ecol. Packag. 10, 631-637 (2007).

27. Segata, N. et al. Metagenomic biomarker discovery and explanation. Genome Biol. 12, R60 (2011).

28. Arbizu, M. P. \& pairwiseAdonis Pairwise multivariate comparison using adonis,. https://github.com/pmartinezarbizu/pairwiseAdonis (2017).

29. Clarke, K. R. \& Ainsworth, M. A method of linking multivariate community structure to environmental variables. Mar. Ecol. Ser. 92, 205 (1993).

30. Legendre, P. \& Gallagher, E. D. Ecologically meaningful transformations for ordination of species data. Oecologia. 129, 271-280 (2001).

31. Wickham, H., François, R., Henry, L. \& Müller, K. dplyr: a grammar of data manipulation. Version 0.8.3. http://dplyr.tidyverse.org/ (2019).

32. Chen, G. et al. Enhancing the systems productivity and water use efficiency through coordinated soil water sharing and compensation in strip-intercropping. Sci. Rep. 8, 1-11 (2018).

33. Gaiser, T., De Barros, I., Lange, F. M. \& Williams, J. R. Water use efficiency of a maize/cowpea intercrop on a highly acidic tropical soil as affected by liming and fertilizer application. Plant Soil. 263, 165-171 (2004).

34. Munisse, P., Jensen, B. D., Quilambo, O. A., Andersen, S. B. \& Christiansen, J. L. Watermelon intercropped with cereals under semi-arid conditions: an on-farm study. Exp. Agric. 48, 388 (2012).

35. Yu, Z. et al. Impact of land use, fertilization and seasonal variation on the abundance and diversity of nirS-type denitrifying bacterial communities in a Mollisol in Northeast China. Eur. J. Soil Biol. 85, 411 (2018).

36. Latati, M. et al. The intercropping cowpea-maize improves soil phosphorus availability and maize yields in an alkaline soil. Plant Soil. 385, 181-191 (2014).

37. Oseni, T. O. Evaluation of sorghum-cowpea intercrop productivity in savanna agro-ecology using competition indices. J. Agric. Sci. 2, 229 (2010).

38. Sikirou, R. \& Wydra, K. Effect of intercropping cowpea with maize or cassava on cowpea bacterial blight and yield. J. Plant Dis. Prot. 115, 145-151 (2008).

39. Tatti, E. et al. Influences of over winter conditions on denitrification and nitrous oxide-producing microorganism abundance and structure in an agricultural soil amended with different nitrogen sources. Agric. Ecosyst. Environ. 183, 47-59 (2014). 
40. Yang, Y. D. et al. Ammonia-oxidizing archaea and bacteria responding differently to fertilizer type and irrigation frequency as revealed by Illumina Miseq sequencing. J. soils sediments. 18, 1029-1040 (2018).

41. Ngwira, A. R., Aune, J. B. \& Mkwinda, S. On-farm evaluation of yield and economic benefit of short term maize legume intercropping systems under conservation agriculture in Malawi. F. Crop. Res. 132, 149-157 (2012).

42. Namatsheve, T., Cardinael, R., Corbeels, M. \& Chikowo, R. Productivity and biological N 2-fixation in cereal-cowpea intercropping systems in sub-Saharan Africa. A review. Agron. Sustain. Dev. 40, 1-12 (2020).

43. Hinsinger, P. et al. P for two, sharing a scarce resource: soil phosphorus acquisition in the rhizosphere of intercropped species. Plant Physiol. 156, 1078-1086 (2011).

44. Zhang, W. et al. Temporal dynamics of nutrient uptake by neighbouring plant species: Evidence from intercropping. Funct. Ecol. 31, 469-479 (2017).

45. Chen, Y. P. et al. Phosphate solubilizing bacteria from subtropical soil and their tricalcium phosphate solubilizing abilities. Appl. soil Ecol. 34, 33-41 (2006).

46. Panhwar, Q. A. et al. Biochemical and molecular characterization of potential phosphate-solubilizing bacteria in acid sulfate soils and their beneficial effects on rice growth. PLoS One. 9, e97241 (2014).

47. Lauber, C. L., Strickland, M. S., Bradford, M. A. \& Fierer, N. The influence of soil properties on the structure of bacterial and fungal communities across land-use types. Soil Biol. Biochem. 40, 24072415 (2008).

48. Campbell, B. J., Polson, S. W., Hanson, T. E., Mack, M. C. \& Schuur, E. A. G. The effect of nutrient deposition on bacterial communities in Arctic tundra soil. Environ. Microbiol. 12, 1842-1854 (2010).

49. Zhang, H. et al. Effects of intercropping on microbial community function and diversity in continuous watermelon cropping soil. Fresenius Env. Bull. 24, 3288-3294 (2015).

50. FU, Z. et al. Effects of maize-soybean relay intercropping on crop nutrient uptake and soil bacterial community. J. Integr. Agric. 18, 2006-2018 (2019).

51. Poggio, S. L. Structure of weed communities occurring in monoculture and intercropping of field pea and barley. Agric. Ecosyst. Environ. 109, 48-58 (2005).

52. Li, P. et al. Cultivation of drought-tolerant and insect-resistant rice affects soil bacterial, but not fungal, abundances and community structures. Front. Microbiol. 9, 1390 (2018).

53. Zhou, X., Wang, Z., Jia, H., Li, L. \& Wu, F. Continuously monocropped Jerusalem artichoke changed soil bacterial community composition and ammonia-oxidizing and denitrifying bacteria abundances. Front. Microbiol. 9, 705 (2018).

54. Gong, X. et al. Responses of rhizosphere soil properties, enzyme activities and microbial diversity to intercropping patterns on the Loess Plateau of China. Soil Tillage Res. 195, 104355 (2019).

55. Zhang, M., Wang, N., Hu, Y. \& Sun, G. Changes in soil physicochemical properties and soil bacterial community in mulberry (Morus alba L.)/alfalfa (Medicago sativa L.) intercropping system. 
Microbiologyopen. 7, e00555 (2018).

56. Asaf, S., Numan, M., Khan, A. L. \& Al-Harrasi, A. Sphingomonas: from diversity and genomics to functional role in environmental remediation and plant growth. Crit. Rev. Biotechnol. 40, 138-152 (2020).

57. Bhattacharyya, P. N. \& Jha, D. K. Plant growth-promoting rhizobacteria (PGPR): emergence in agriculture. World J. Microbiol. Biotechnol. 28, 1327-1350 (2012).

58. Castro, J. F. et al. Blastococcus atacamensis sp. nov., a novel strain adapted to life in the Yungay core region of the Atacama Desert. Int. J. Syst. Evol. Microbiol. 68, 2712-2721 (2018).

59. Castro, J. F. et al. Geodermatophilus chilensis sp. nov., from soil of the Yungay core-region of the Atacama Desert, Chile. Syst. Appl. Microbiol. 41, 427-436 (2018).

60. Griffiths, B. S. \& Philippot, L. Insights into the resistance and resilience of the soil microbial community. FEMS Microbiol. Rev. 37, 112-129 (2013).

\section{Figures}


A

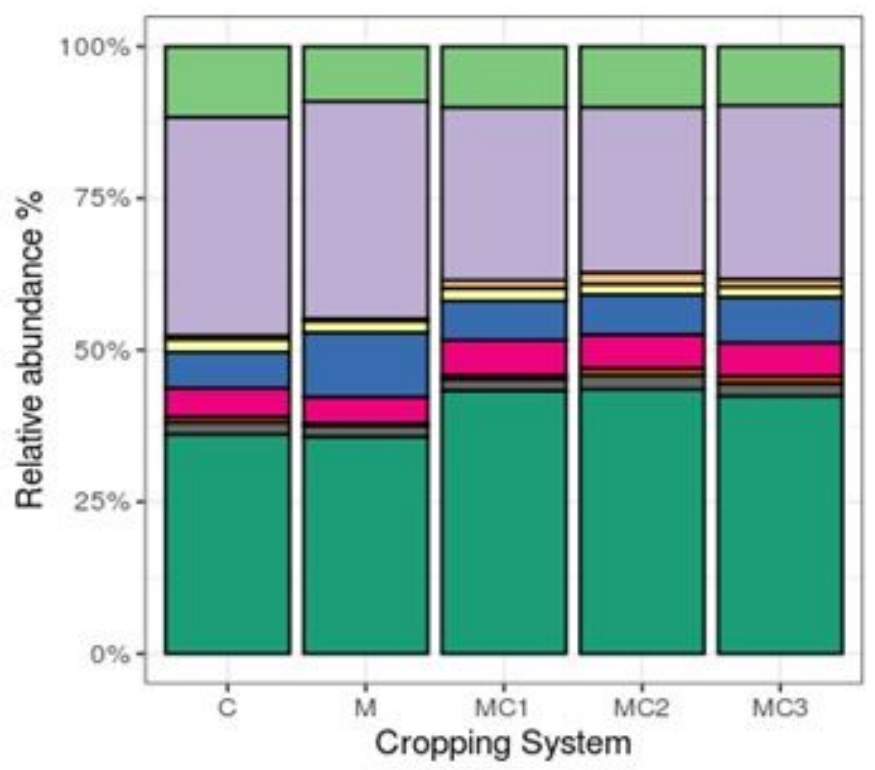

Phylum

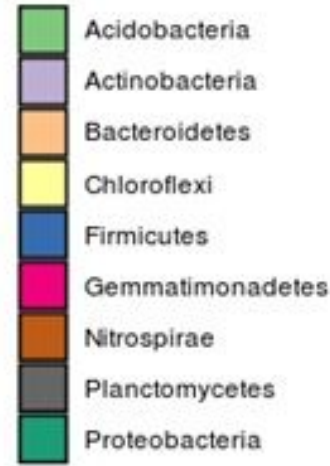

Genus

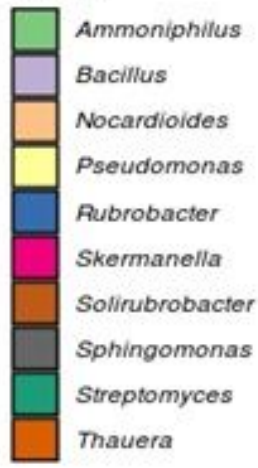

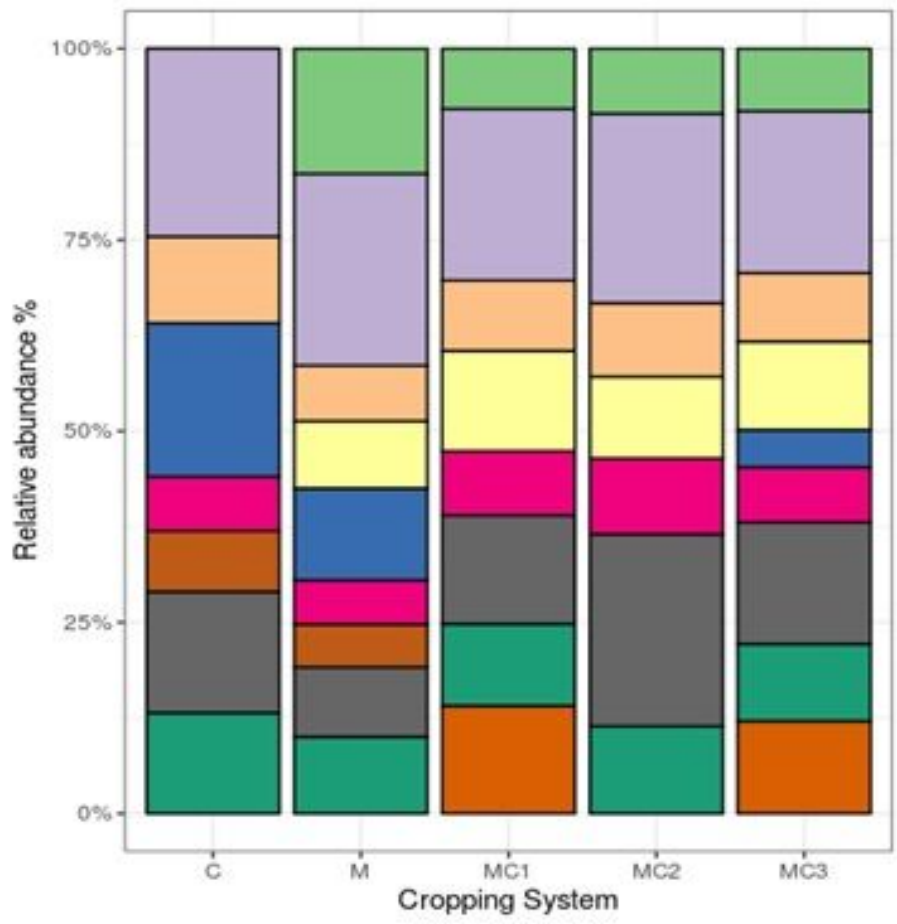

\section{Figure 1}

Relative abundance $(>1 \%)$ at $(A)$ phylum and (B) genus level of soil bacterial community of intercropping systems. Barplot represents the average of samples for each taxon in each cropping system $(n=5)$. C, cowpea monocrop; $\mathrm{M}$, melon monocrop; $\mathrm{MC1}$, mixed intercropping; $\mathrm{MC2}$, row intercropping 1:1; $\mathrm{MC}$, row intercropping 2:1. 


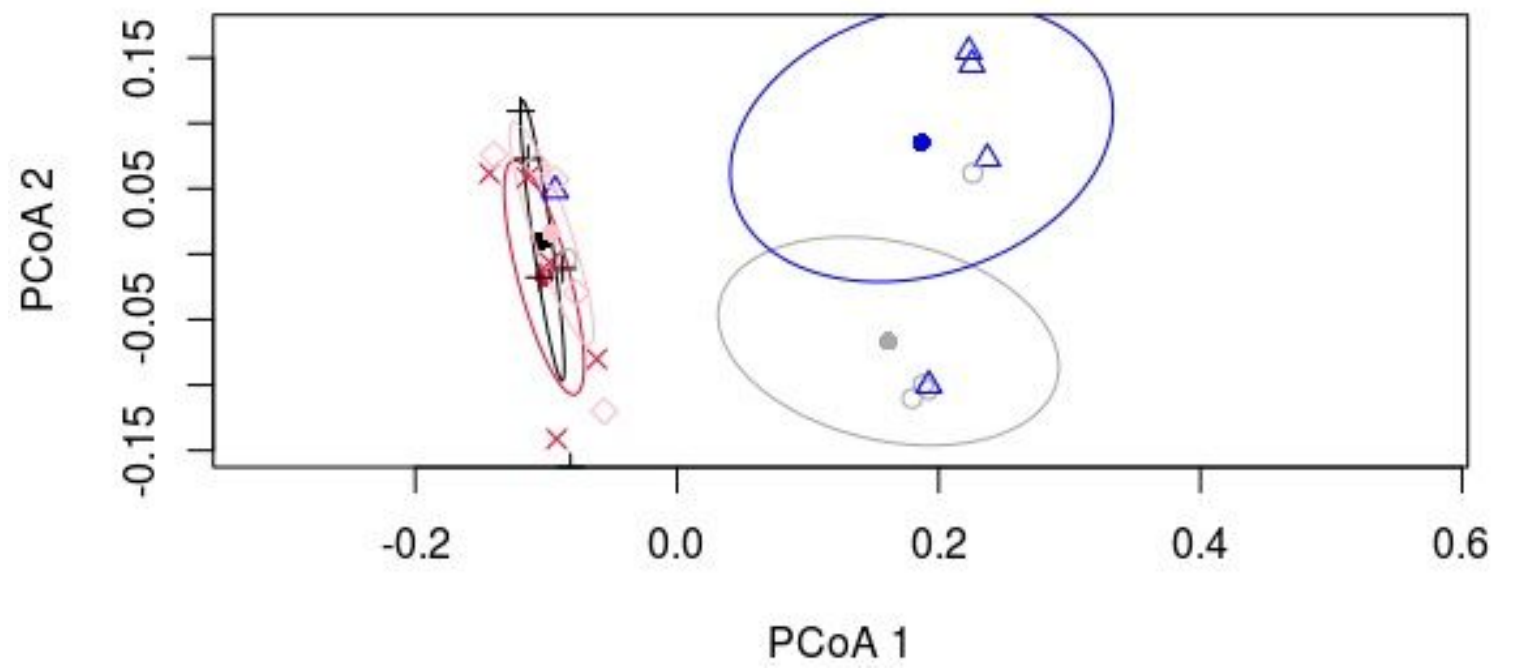

Figure 2

Principal Coordinate Analysis (PCOA) of bacterial distributions in different intercropping systems. PCoA displays group centroids and dispersions. $\mathrm{C}$, cowpea monocrop; $\mathrm{M}$, melon monocrop; $\mathrm{MC1}$, mixed intercropping; $M C 2$, row intercropping 1:1; $M C 3$, row intercropping 2:1.

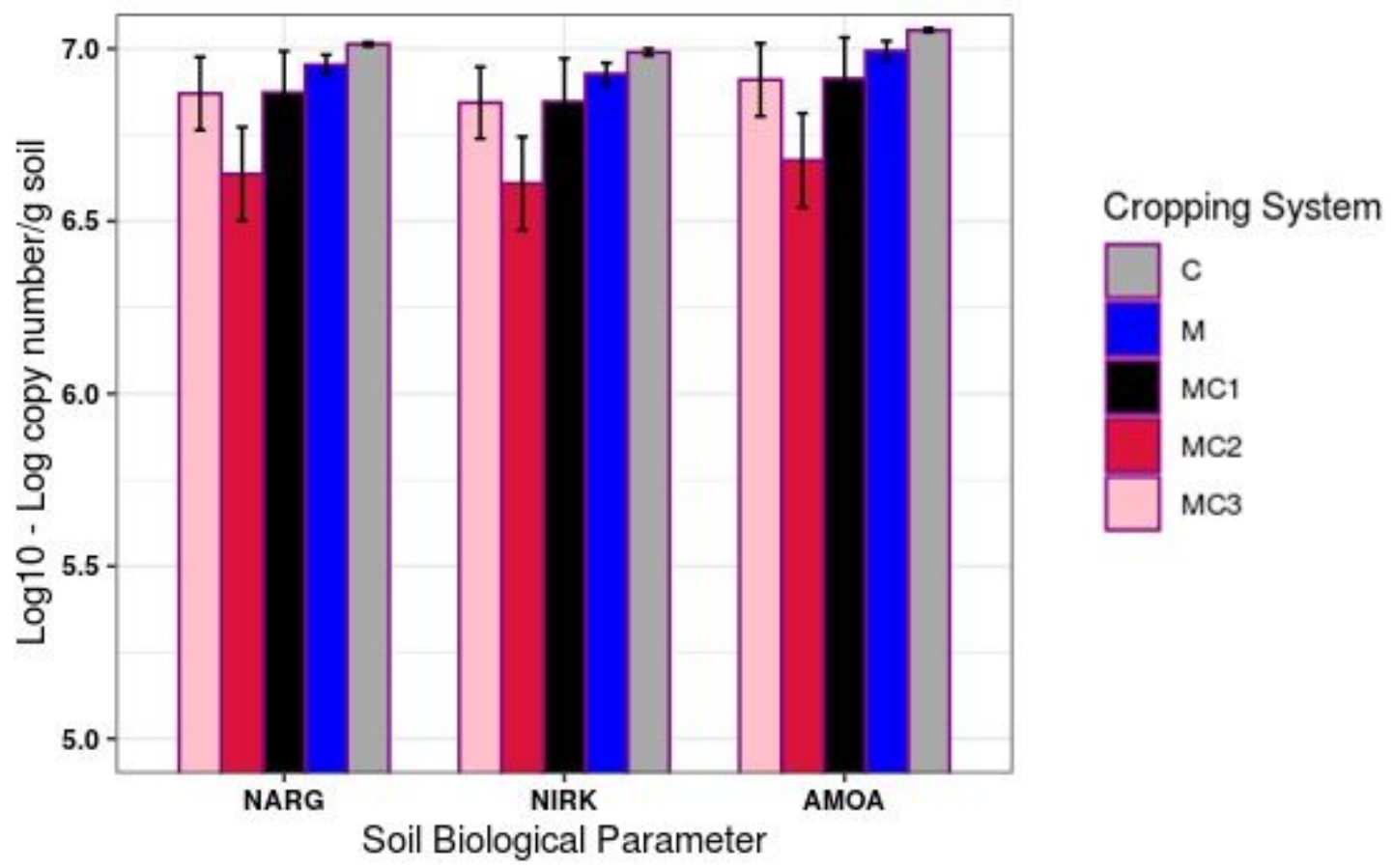

Figure 3

Influence of intercropping on abundance of NARG, NIRK and AMOA genes belong to soil N cycle. (Bars represent means \pm sd; $n=5$ ); C, cowpea monocrop; $M$, melon monocrop; $M C 1$, mixed intercropping; $M C 2$, row intercropping 1:1; MC3, row intercropping 2:1; NARG, narG gene; NIRK, nirK gene; AMOA, amoA gene. 


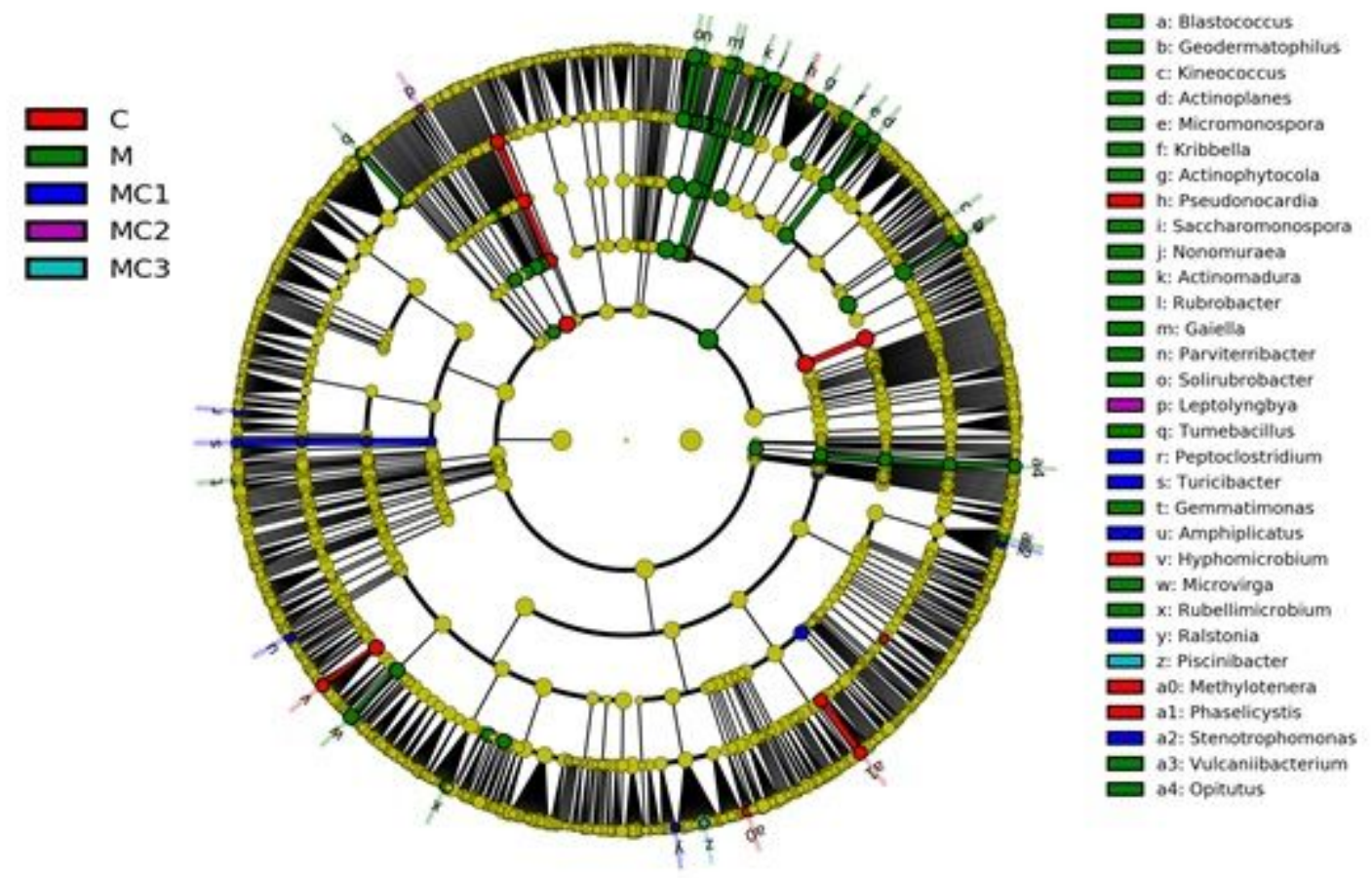

Figure 4

Cladogram indicating the polygenetic distribution of bacterial lineages at genus level in the intercropping systems as determined by linear discriminant analysis (LDA) effect size (LEfSe). Each circle's diameter is proportional to the taxon's abundance. C, cowpea monocrop; M, melon monocrop; MC1, mixed intercropping; MC2, row intercropping 1:1; MC3, row intercropping 2:1. 


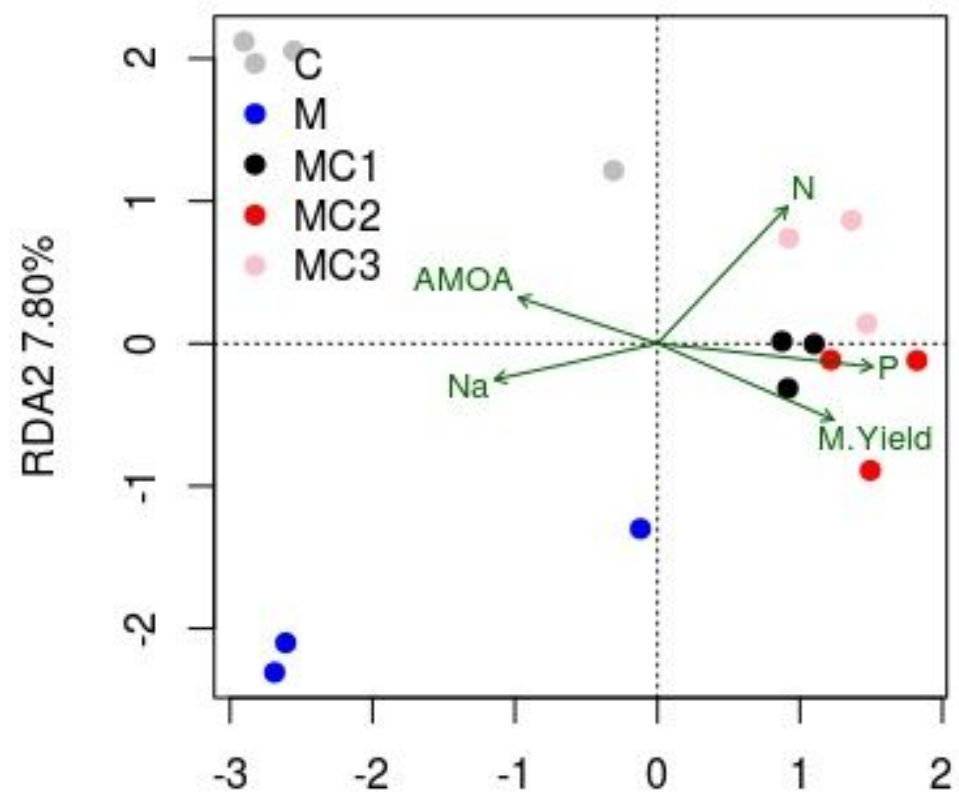

RDA1 $13.11 \%$

Figure 5

Redundancy analysis (RDA) based on bacterial community composition of intercropping systems. Sites are coloured by cropping system whereas vectors show the correlation of the chemical, biological and harvest parameters with the community. $\mathrm{Na}, \mathrm{P}$, available $\mathrm{Na}, \mathrm{P} ; \mathrm{N}$, total nitrogen; $\mathrm{M}$. Yield, melon yield; $\mathrm{C}$, cowpea monocrop; $\mathrm{M}$, melon monocrop; $\mathrm{MC1}$, mixed intercropping; $\mathrm{MC2}$, row intercropping 1:1; $\mathrm{MC}$, row intercropping 2:1.

\section{Supplementary Files}

This is a list of supplementary files associated with this preprint. Click to download.

- CS16SUPLEMENTARIOFV.doc 